\title{
Control as a Core Component of User Involvement in Reablement: A Qualitative Study
}

This article was published in the following Dove Press journal:

Journal of Multidisciplinary Healthcare

\author{
Kari Jokstad $\mathbb{D}^{1,2}$ \\ Solveig Hauge \\ Bjørg Th Landmark' \\ Kirsti Skovdahl' \\ 'Faculty of Health and Social Sciences, \\ University of South-Eastern Norway, \\ Drammen, Norway; ${ }^{2}$ Department of \\ Health and Social Welfare, Drammen, \\ Norway
}

Background: Reablement, also known as restorative care, supports older adults in regaining or maintaining their independence in daily life through the optimization of functional ability. Users' goals and healthcare professionals' use of a "hands-off" approach are key, thus user involvement is central to reablement logic. The aim of this study was to explore user involvement in reablement from users' perspectives from the beginning of an intervention.

Methods: The study has an explorative qualitative design and includes thematic content analysis of data from repeat, individual semi-structured interviews with ten users accepting reablement intervention services in an urban Norwegian municipality.

Findings: Control emerged as a core component. Users handed control over their time and body to professionals, balanced by drawing on an inner strength to control own limits, retain the right to make own judgements and decisions, and dream. Five themes were seen: Positive, but with a "wait and see" attitude; Professionals have goals, users have dreams; Desire to control schedule and activity; Regaining faith in one's own capacity and strengthening one's dreams; and Keep going, hold on to your dreams.

Conclusion: User involvement interpreted as user-set goals may be over-emphasized. Users possess the information that professionals need to set goals, consider these the goals important for professionals, and seek to facilitate professionals in their work. Based on a belief in own competence and a trust in professional's expertise, users invite professionals into a co-creation process. User involvement has previously been defined as a willingness and positive attitude toward reablement activities, but we find it can be expressed in different ways. Reablement logic does not always match users' understanding or desires, and it may be time to rethink user involvement in reablement. The reablement concept should be developed further, so that it better suits the individuals it should serve.

Keywords: goal-setting, older adults, home-care services, restorative care

\section{Background}

The World Health Organization (WHO) proposes that 2020 to 2030 be declared the Decade of Healthy Aging. ${ }^{1}$ The WHO defines healthy ageing as the process of developing and maintaining functional ability that enables well-being in older age. The WHO maintains that autonomy is a core component of well-being and finds that the maximization of intrinsic capacity, i.e., all the physical and mental capacities an individual can draw on, is a key action for enabling autonomy. ${ }^{2}$ To orient long-term care services toward the goal of optimizing functional ability, reablement, also known as restorative care, is offered in many high-income countries. ${ }^{3}$ Reablement is a timelimited, intensive, multidisciplinary, person-centered and goal-directed intervention ${ }^{4}$ through which older adults are supported in regaining or maintaining their
Correspondence: Kari Jokstad

Email kari.jokstad@usn.no
Journal of Multidisciplinary Healthcare 2020:13 1079-1088

1079 
independence in daily life. ${ }^{3}$ Reablement is based on individual needs and wishes and emanates from a user's goals, ${ }^{5}$ in accordance with the user's perceptions of the impact that his/ her health challenges have on everyday life. User involvement, consequently, is an important aspect of reablement and has been highlighted in many quality reforms and standards. ${ }^{6,7}$ Rooted in consumerist ideology and considered a democratic right, in the context of healthcare service delivery user involvement can be understood as a userprofessional relationship in which individuals' right to influence and become involved is connected to a simultaneous duty and responsibility to make good choices that allow them to be independent and self-reliant for as long as possible. ${ }^{8,9}$

User involvement in reablement constitutes both an aim and a method. The goal-setting process is a key component, and the inclusion of users' goals into the reablement process is considered instrumental to the success of an intervention. ${ }^{10-13}$ Allowing users to set own goals facilitates motivation for the intervention. ${ }^{14,15}$ Another key component is users' independence, which can include that professionals adopt a "hands-off" approach. ${ }^{16,17}$ The purpose of a hands-off approach is to prevent users from becoming passive help and care recipients and instead enable active participation and regained independence through optimized functional ability. Still, some researchers find that users can have problems setting goals, ${ }^{13,18,19}$ linked to users' lack of motivation or ability to understand the purpose of an intervention ${ }^{12,13,15,18}$ or limited professional communicative competence. ${ }^{20,21}$ Users' difficulties with goal-setting can lead to goals being set by professionals. ${ }^{20,22,23}$ More knowledge on user involvement from the perspective of older adults is needed to further improve reablement and enable the customization of interventions for all the individuals that reablement should serve. During a search for literature, a limited number of internationally published studies exploring users' experiences of reablement were found, and these employed a retrospective perspective. The aim of this study was to explore user involvement in reablement from users' perspectives from the beginning of a reablement intervention.

\section{Methods}

\section{Design}

The study has an explorative qualitative design. The data material was created through repeat, individual semistructured interviews. ${ }^{24}$

\section{Context and Participants}

The setting was an urban municipality with 70,000 inhabitants in Southeastern Norway where reablement had been implemented in home-care services 1.5 years prior to the study. A reablement intervention starts with users receiving a visit from a multidisciplinary team. During this initial visit, activity mapping and physical assessment measurements using the Canadian Occupational Performance Measure (COPM) ${ }^{25}$ and Short Physical Performance Battery (SPPB $)^{26}$ instruments occur. General information about the intervention is given alongside conversation. After this visit, the team creates individual, written rehabilitation plans in which goals and daily activities for a six-week intervention are delineated; all users receive a copy. When the six-week intervention is completed, the process is repeated. The team and users together summarize the intervention process and determine whether there is any eventual further need for home-care services.

For the purposes of this study, all service users who had accepted reablement intervention services in the municipality were considered potential study participants. During the initial assessment visit described above, users were asked whether they would like to participate in the study. If consent was given, study researcher KJ first contacted the potential participants by phone and then, pursuant to agreement, conducted a home visit. During the home visit, KJ provided further information about the study and, for those providing their consent to participate, conducted the first interview.

During the recruitment period, 29 service users started a reablement intervention. Of these, 19 were not included in the study for several reasons (Figure 1). A total of 10 participants were included in the study, six women and four men aged 62 to 93 years. For a participant overview, based on the participants' information, see Table 1. In this study, the term professional is used to represent all of the different healthcare professionals part of the reablement team.

\section{Data Collection}

Supported by an interview guide, three individual interviews with each participant were conducted by KJ at sixweek stages during the reablement intervention: interview $\mathrm{A}$ at the start, interview $\mathrm{B}$ at the end, and interview $\mathrm{C}$ after the intervention. An advisory group composed of five older adults with previous experience of reablement 


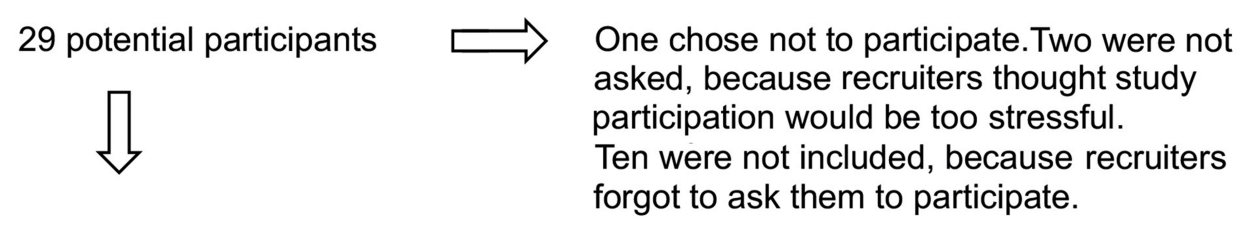

16 agreed to participate

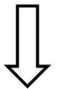

15 contacted by telephone

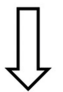

13 received a home visit<smiles>[C]=C</smiles>

10 participated in interview A

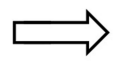<smiles>[C]1C=C1</smiles>

9 participated in interviews B and C
One was hospitalized and her intervention terminated.

One withdrew during the telephone call. One withdrew the next day, because of hospitalization.

Two withdrew during the home visit, because participation was too overwhelming. One withdrew during the home visit, because she had also withdrawn from the reablement intervention.

One reablement intervention was terminated after 3 weeks, because of illness.

One audio file from interview $\mathrm{C}$ was damaged.

Figure I Flowchart for the recruitment of potential participants.

contributed to the development of the semi-structured interview guide. The interview guide consisted of openended questions, which helped participants talk about what they experienced as being important to them. ${ }^{24}$ The interview guide themes related to participants' perceptions, expectations and experiences of the goal-setting process and reablement intervention, including own involvement and role during the intervention and thoughts about the future. The data collection period lasted from May 2017 to February 2018. The interviews lasted for 45-75 minutes and were audio recorded. The data material consisted of 27 interviews in total $(10+9+8)$.

Each interview started with small talk about the participants' current situation, followed by the interview guide themes. In interviews $\mathrm{B}$ and $\mathrm{C}$, the initial small talk included discussion of the time that had elapsed since the last interview, allowing participants to identify topics they wished to discuss in further detail. KJ wrote memos immediately after each interview, which included a description of the interview context and immediate reflections. Before each subsequent interview (a maximum of two days before), KJ listened to the audio recordings and read the memos from the previous interview.

\section{Analysis}

Thematic content analysis inspired by the framework of Brinkmann and Kvale ${ }^{24}$ was used for analysis. KJ listened to all 27 collected interviews, grouped by participants, to gain an overall impression of the content. KJ then transcribed these 27 interviews verbatim, grouped by stage (A, $\mathrm{B}, \mathrm{C})$. To narrow the data material, interviews from six randomly selected participants were extracted, yielding eighteen interviews for the main analysis.

To look for preliminary themes, KJ re-read all eighteen extracted interviews while the other three members of the research team read six interviews each. Grouped by stage, the preliminary themes were discussed by the research team, then summarized by KJ and validated by the team. 
Table I The Participants

\begin{tabular}{|c|c|c|c|c|c|}
\hline Gender & Age & Reason for Reablement & $\begin{array}{l}\text { Home-Care Service prior } \\
\text { to the Intervention }\end{array}$ & $\begin{array}{l}\text { Home-Care Service } \\
\text { After the Intervention }\end{array}$ & $\begin{array}{l}\text { Living } \\
\text { Situation }\end{array}$ \\
\hline Female & 87 & Sudden functional decline & No & No & Alone \\
\hline Male & 77 & Gradual functional decline & Yes & Yes & Spouse \\
\hline Female & 81 & Gradual functional decline & No & No & Alone \\
\hline Female & 93 & Sudden functional decline & No & Yes & Alone \\
\hline Male & 80 & $\begin{array}{l}\text { Gradual functional decline followed by } \\
\text { sudden functional decline }\end{array}$ & No & No & Alone \\
\hline Male & 62 & $\begin{array}{l}\text { Gradual functional decline followed by } \\
\text { sudden functional decline }\end{array}$ & No & No & Spouse \\
\hline Female & 80 & $\begin{array}{l}\text { Gradual functional decline followed by } \\
\text { sudden functional decline }\end{array}$ & Yes & Yes & Spouse \\
\hline Male* & 83 & Sudden functional decline & No & No & Spouse \\
\hline Female & 82 & Gradual functional decline & Yes & Yes & Alone \\
\hline Female** & 82 & Gradual functional decline & Yes & Yes & Alone \\
\hline
\end{tabular}

Notes: *Damaged audio file, interview C. **The intervention was terminated after three weeks, because of illness.

From the validated themes, questions related to different aspects of user involvement were developed. For example, How do users describe their expectations for the intervention period? How did users' goals emerge? How do users experience own influence and involvement during the intervention?

To reduce the data to text relevant to the study aim, meaning units were identified from these questions, and grouped by stage. The meaning units were then condensed. Themes were elicited from the condensed meaning units, through a back-and-forth dialogue between the parts and the whole. To ensure that the context was understood and the condensed meaning units were linked to the most logical theme, parts of the eighteen extracted interviews included in the main analysis were re-read, resulting in some meaning units being moved to other themes. Lastly, to look for additional meaning units, $\mathrm{KJ}$ re-listened and reread those interviews not included in the main analysis. This reading revealed that the content of the eighteen extracted interviews was encompassed by the themes created during the main analysis process.

\section{Ethical Approval and Consent to Participate}

The Regional Committee for Medical and Health Research Ethics evaluated the study but did not consider it to fall under the provisions of the Health Research Act (REK South East, reference no. 2017/11). The Norwegian Centre for Research Data (NSD, reference no. 53,736) gave consent for the collection and storage of the study data. Throughout the entire study, we have adhered to the guidelines set forth in the WMA Declaration of Helsinki. ${ }^{27}$ The participants gave written, informed consent before the interviews, including consent to publication of anonymized responses, and were informed about their right to withdraw at any time.

\section{Findings}

The following five themes were seen. At the start of the intervention (A): Positive, but with a "wait and see" attitude; Professionals have goals, users have dreams. At the end of the intervention (B): Desire to control schedule and activity; Regaining faith in one's own capacity and strengthening one's dreams. Six weeks after the intervention (C): Keep going, hold on to your dreams.

\section{At the Start of the Intervention (A) Positive, but with a "Wait and See" Attitude}

The participants described the offer of a reablement intervention as being unexpected and a bit overwhelming. Some could identify who had first mentioned the intervention, e.g., a familiar home-care service nurse, while others were uncertain. The participants referred to the intervention as something that the professionals had already decided on.

They just came. I must to be sure have said yes. (P1)

Some welcomed the intervention, perceiving it as an opportunity to improve their functional capacity. Others stated they just waited to see what would happen. One observed, 
It is open. I take it as it comes. I do not require so much. (P2)

Some participants even expressed ambivalence about the intervention, noting concerns related to whether the professionals would demand more than they could cope with or physically do. One participant questioned what she would gain from the intervention, noting that she felt she had the right to set limits.

I am a lite unsure of what the content of the coming weeks will be. Is it something I do not [like the look of], I say no. I will do this then. Forcing oneself to [do] something is not funny. But, when you think of it, one should not be negative to it either, because it is often that you think that it is something you cannot manage, and then you see [that] it is fun once you get started. I want to see whether it is something I can learn a little from. (P3)

The participants were also concerned that frequent intervention-related visits would interfere with daily routines or take up too much time.

Yet, as much as I am alone you would almost think that it would be fun. But now I have these times to all the time [keep track of] ... I think it will be a little too often. There is something practically every day. I need it of course, but .... (P4)

We discerned that the participants displayed a "wait and see" attitude regarding the intervention. They demonstrated awareness of their situation when they noted that the intervention was necessary and did not question their own wants regarding participating in the intervention. They assumed that the intervention would challenge their physical capacity and require a lot of their time.

\section{Professionals Have Goals, Users Have Dreams}

While the participants recalled an initial assessment visit, they had difficulty expressing specific details. They stated that they had provided information and performed practical and physical tasks, e.g., walking on a line or standing on one leg. They perceived that the atmosphere of the visit was comfortable, despite experiencing that the physical tasks were challenging and reminded them of their physical limitations. They noted that the conversation and assessments were necessary and allowed the professionals to plan and design the intervention.

It was a physiotherapist who measured how far I could walk here inside in order to have the basis for a training program for me. So there were questions about social contacts. This as a starting point for these people to make decisions about what they can do for me. (P5)

Some participants barely registered that they had received a written rehabilitation plan; they could not remember where it was and could only generally explain its content. When the interviewer $(\mathrm{KJ})$ read the plan aloud to them, they recognized the goals, but did not devote further attention to the subject other than referring to the different exercise-related activities. Still, they spoke of the future, using cautious terms such as dreams, hopes, yearning or desires. All expressed a broad, general hope that they would "get better" but questioned whether this was possible due to their decreased functional capacity: a body they could neither trust nor control. One yearned to visit friends; another missed being independent and moving around without help, where and when she wanted. Others described what they had previously done or who they used to be, which we interpret as the participants conveying their dreams.

I take one day at a time, have done this a long time now (pause). I miss being a little more outside than what I am [now], because I have always been an outdoor person, been fond of being outside. (P3)

The participants revealed that they sought to facilitate the professionals in their work. We discerned that the participants perceived that the professionals were focused on goals and goal-setting and interpret the participants' actions as allowing the professionals to make decisions about how functional capacity could be improved without "intervening", while still dreaming about what they would like to do. We perceived that their dreams were based on lived experiences, which they associated with positive memories and feelings and now missed.

\section{At the End of the Intervention (B) Desire to Control Schedule and Activity}

The participants revealed that the professionals could occasionally reschedule visits, but that they themselves seldom did so. They stated that they adjusted their day to meet the professionals' schedule, because they perceived that the professionals were busy.

There were people here time and again. I had scheduled times. I think it went well. I am very pleased. (P2)

While some participants easily adapted to the professionals' schedule, others noted that they found the times for the visits to be inconvenient. 
I would be happy to have a little time for myself in the morning. In the bathroom and so on. Once I had to [answer the door] in [my] nightgown and robe. I did not like that. (P4)

Still, this participant revealed that she had not mentioned her preferences to the professionals, despite the frustration she experienced; she felt that she should accept and adapt to their schedule.

The participants were, however, willing to express themselves about the number of exercise-related activities they performed together with the professionals. All of the participants mentioned that they had days when they experienced pain and did not have the energy to carry out the activities as planned, and perceived that the professionals accepted their demurrals. One participant related that she was met with understanding when she asked to reduce the length of the day's walk:

It happened that there were some days that I said that now

I must take it easy. And it went well. I decided then. (P1)

During the intervention, the participants were given an exercise program to perform on their own. The participants revealed that they completed the exercises in line with how they were feeling on the given day, although this could differ from what was written in their program. One participant stated that even though he understood the benefit of following the professionals' recommendations, he thought it was vital that he make independent decisions.

I have understood that it has been necessary, I have allowed myself to be steered. I want to have the feeling that I can do a little more when it suits [me], manage it myself, in accordance with circumstances ... I must have the feeling that I have control over what I should do. Then I have a grip on the development. I do not think I would feel comfortable if others would decide down to the smallest detail what I should do when. (P5)

We found that the participants to some extent allowed professionals to make decisions, yet assumed and defended the right to own independent decision-making. We perceived that the participants believed that they alone should control their actions, including exercise-related activities with professionals and exercise without professionals, manifested in the form of independent decisions.

\section{Regaining Faith in One's Own Capacity and Strengthening One's Dreams}

The participants stated that they developed competence and confidence regarding own physical capacity during the intervention. They revealed that they had been challenged to try activities that they at the start of the intervention did not believe themselves capable of.

They got me up and running so well! I had to be sure such nice training with [my] polio foot. I have [put weight on it] completely incorrectly. They showed me how I should [put weight on my foot], and watched while I walked. They walked behind me and 'shuffled me' along (laughs). Yes, but it was very much all right. It remains with me, and now I put [weight on] my foot as I should. It was something I never had thought about or known. (P3)

We found that the participants' experiences of renewed mastery and control facilitated their faith in own capacity and helped them strengthen their dreams. The same participant as above, who six weeks previously lived one day at a time but now reveled in her new-found ability to walk, also stated

It is three years since I was at the cabin. I long for [it] to be sure. But I hope that if I get to live, that I can go there again ... Yes, [now I] think more than one day at a time. No, I was not good [six weeks ago]. That I can see. (P3)

We found that the participants drew on an inner strength when professionals' visits were demanding. One participant related that a therapist asked her to take a shower. She thought the therapist would assist, but soon realized the therapist merely wanted to observe. Even though she was upset about this, she did not protest and managed to complete the task.

She sat down in a chair and just watched. I almost could not handle that, like. Is that person sitting there and cannot hand me the towel even once, I thought. But I thought: I will in any case wash myself properly. And then I didn't break down, because then I was a little angry. Quite simply. Then I would manage myself. She didn't help me at all, but I had expected this. I got really upset over this. (P4)

We found that the participants increased their physical capacity and strengthened their dreams, even daring to hope, when their limits were tested in co-operation with professionals. When participants and professionals shared expectations and understanding, they became partners in a common project. When this did not occur, the participants' integrity was compromised. Still, the participants were able to draw on an inner strength that allowed them to regain control over their experience of the situation. 


\section{Six Weeks After the Intervention (C) Keep Going, Hold on to Your Dreams}

The participants related that they found it satisfying to regain control and flexibility over their everyday life once the intervention was completed. They remembered the intervention period as being busy, with frequent visits from the professionals. They recalled that they were unable to independently manage their time or engage in certain activities, e.g., baking, walking the dog, grocery shopping. Still, the participants noted that many positives had come from their participation in the intervention. One participant revealed that a dream that was strengthened during the intervention had come true. "Oh it was so lovely, because then we [did] something I have dreamt of ... to walk on paths with sand and a little moss. It was lovely!". Another noted how it was easier to try new activities after the intervention.

That support, that you have a feeling of, even if it is [because of] professionals, that there are several who hope that you should get on your feet again. The physical, but also the mental - get people who care with you. To feel that [someone] has [your back]. (P6)

The participants emphasized that the professionals' skills and competence were instrumental to the progress they made, while simultaneously downplaying that care was provided by several different actors.

The most essential is that they represented a system that eventually worked very well. Different people came every day. I did not get to know them, so there were no personal relationships. But the most important was that they knew the task and completed it in a professional manner. (P5)

Even though they experienced that their physical capacity had increased, which they appreciated, they nevertheless revealed that it was demanding to continue to maintain the same level of activity. Some participants revealed that their progress had stalled after the intervention, while others noted that their progress still continued. Yet the participants nevertheless sought to fulfill the dreams that had strengthened during the intervention.

I would like to become better. But I am uncertain whether everything can become so very much better. Limited by the physical pain. I must just wait and see. [Becoming active] with [my] knees, I think that I must leave that to a higher power, so to speak. The spirit is willing, but the flesh is weak. (P5)
We found that the time after the intervention was a transitional period, during which the participants sought to adjust to their changed life situation. They continued to demonstrate the same inner strength that helped strengthen their dreams during the intervention, even noting that such was essential, while also expressing that they valued the new physical capacity they had.

\section{Discussion}

The aim of this study was to explore user involvement in reablement from users' perspectives. Our overall interpretation of the findings is that control is a core component of user involvement in reablement. There was a duality to the nature of the control seen, which emerged as external control exercised by professionals and internal control exercised by users. We discerned that during the reablement intervention the participants handed control over their time and body to the professionals and allowed the professionals to make decisions. This was balanced by the participants drawing on an inner strength to control limits, retain the right to make own judgements and decisions, and dream. Thus, we find that the boundaries that defined who was in control fluctuated throughout the intervention.

We initially saw that the participants were generally positive toward the intervention, albeit with a "wait and see" attitude. Björkman Randström et al find that users set goals for both the immediate future and longer term. ${ }^{28}$ Hjelle et al find that goal-setting is important for users to look forward and that user motivation is stimulated through defining own goals. ${ }^{14}$ We perceived that the participants here did not take an active role in the process nor demonstrated user control during the goal-setting process. One possible explanation for the differences seen between the findings of our study and others' studies can lie in methodology. While other studies are retrospective i.e., users' goals are explored after an intervention, we have incorporated an approach in which participants were interviewed at the start of, at the end of, and after an intervention. This led to the immergence of new knowledge; for example, we saw that the participants expressed their dreams and desires more clearly at the end of the intervention. It is possible that experienced increased functional capacity can retrospectively facilitate the expression of dreams and desires, in the form of perceived intervention goals.

Limited user involvement in the goal-setting process has been seen in other studies, and other researchers attribute this to users' lack of understanding of the intervention 
or that users are passive or unmotivated. ${ }^{13,15,18,20}$ We however did not perceive that the participants here were passive or unmotivated. Instead, we suggest that perhaps the importance of user-set goals in reablement might be over-emphasized. Individuals who could benefit from reablement may be excluded if motivation is equated to userset goals and considered a prerequisite for participation in an intervention.

Allowing professionals to control the goal-setting process can be considered an active, reasonable choice. Challenging health conditions and newly experienced functional decline can make everyday life difficult, and it is understandable that a user's focus may be concentrated on such issues instead of the future. Especially at the beginning of an intervention, when it is difficult to know what to expect, it is logical that one may place greater emphasis on professional expertise, seen as allowing professionals to make decisions. Furthermore, the participants considered the goal-setting process to be important for the professionals. Several studies in which professionals' experiences are explored confirm what we saw here i.e., that professionals emphasize working toward common goals. ${ }^{10,29,30}$ We uphold that the participants here maintained control; by providing professionals with the information needed to set goals and create intervention plans, they facilitated professionals' involvement.

The participants attributed their increased functional capacity to the professionals' skills and competence and their own inner strength. The professional-user relationship appeared to be a dynamic process, a fluctuation between external and internal control where participants and professionals "shared" power by recognizing the other's competence. The participants considered the professionals to be reablement experts and were open-minded to professionals' input and initiatives, which seemed to meet the participants' needs and facilitate their renewed functional mastery and increased inner strength. This is in line with the findings from a previous study, in which user involvement from professionals' perspectives was explored. There we found that users gradually became more capable of verbalizing their desires and participating in co-creation processes when professionals started interventions with small tasks that users could master. ${ }^{19}$ We argue that co-creation can awaken users' minds to new opportunities. When users' hopes and dreams become more concrete and visible, their inner strength and sense of internal control may increase.
Even when facing a new life situation, having a sense of control was important for the participants, and they continued to perceive themselves as being responsible for and in control of their lives. This is in line with Hjelle et al, who found that participants preferred to engage in activities in accordance with day-to-day health conditions. ${ }^{14}$ The participants here also demonstrated an insight into own possibilities and limitations and an understanding of what could be beneficial for them in their current situation. We saw that when professionals violated or ignored users' limits, strong emotions and resistance emerged. In reablement, professionals should employ a hands-off approach, allowing users to be active. ${ }^{16,17}$ There is a risk that users' internal control is threatened when professionals do not communicate such an understanding of user involvement clearly. We saw that the participants here demonstrated resistance, anger, watchfulness and/or negotiation, all of which can be considered active coping mechanisms used to manage distress. The importance of users being motivated and engaged is emphasized in reablement, expressed through users' positive attitudes toward reablement activities. ${ }^{31} \mathrm{We}$ found individual differences in how users accept external control and professionals' involvement. Other researchers find that professionals prioritize users' ability to undertake activities without assistance, while users value making autonomous decisions. ${ }^{32}$ Consequently, professionals should seek to diversify how they express themselves and engage with users, and should take users' various expressions of inner strength and need for internal control into consideration.

\section{Methodological Considerations}

Individual semi-structured interviews can be considered a strength when the purpose is to gain knowledge from the individual's point of view. Another possible strength is the study design because data were collected soon after the experiences being explored. To our knowledge, this is the only study of users' experiences at the start of a reablement intervention. In addition, the involvement of an advisory group composed of individuals with firsthand experience of reablement in developing the interview guide was a strength.

It may be a limitation that the research teams' disciplinary background did not reflect the professional diversity of the professionals involved in the interventions investigated here. Still, the research team included three nurses and one physiotherapist, all with previous clinical experience in community healthcare services. The three 
nurses also had comprehensive research experience and competence, while the physiotherapist had knowledge of reablement. The sample size may be a potential limitation. However, 27 repeat, good-quality interviews yielded a rich data material. The analysis strategy facilitated management of the data gained from the interviews, and the actual sample held adequate information power to develop new knowledge on user involvement in reablement. ${ }^{33}$

\section{Conclusion}

This study contributes to a broadening of the perspectives on user involvement in reablement by contributing insight into users' experiences. The logic previously internalized by professionals during reablement does not always match users' understanding or desires, and we believe it is time to rethink user involvement in reablement. User involvement interpreted as user-set goals at the beginning of an intervention may currently be over-emphasized. We saw that users possess the information that professionals need to set goals and that users consider these the goals to be important for professionals. It is a willful act when users trust professionals' expertise and competence and (appear to) hand over control. When they invite professionals into a co-creation process, they nonetheless are acting based on a belief in own competence. Previously, user involvement in reablement has been defined as a willingness and positive attitude toward reablement activities. We however find that user involvement can be expressed in different ways. Such insight can contribute to the further development of the reablement concept, so that it better suits the individuals it should serve and becomes more relevant for community-based health service leaders and professionals. Further investigation should include (crosscountry) longitudinal studies with the aim to explore users' experiences with rehabilitative interventions in different cultural contexts.

\section{Acknowledgments}

The authors express their gratitude to the participants, who willingly shared their experiences on several occasions. Thanks also to the advisory group, who through their contributions helped improve the quality of the study. KJ's employment is facilitated by Drammen municipality and The Research Council of Norway's public-sector PhD program (project no. 259637/H40). The aim of the $\mathrm{PhD}$ program is to expand research competency and knowledge for doctoral candidates and the public sector body as a whole and to facilitate collaboration between public sector bodies and academia.

\section{Disclosure}

The authors report no conflicts of interest in this work.

\section{References}

1. WHO. Decade of healthy aging. 2019. Available from: https://www.who. int/docs/default-source/decade-of-healthy-ageing/full-decade-proposal /decade-proposal-fulldraft-en.pdf?sfvrsn=8ad3385d_6. Accessed March $10,2020$.

2. WHO. World report on aging and health. 2015. Available from: http://www.who.int/ageing/publications/world-report-2015/en/.

Accessed September 11, 2020.

3. Aspinal F, Glasby J, Rostgaard T, Tuntland H, Westendorp RGJ. New horizons: reablement - supporting older people towards independence. Age Ageing. 2016;45(5):574-578. doi:10.1093/ageing/afw094

4. Cochrane A, Furlong M, McGilloway S, Molloy DW, Stevenson M, Donnelly M. Time-limited home-care reablement for maintaining and improving the functional independence of older adults. Cochrane Database Syst Rev. 2016;10.

5. Ebrahimi VA, Philips S. The centrality of 'service users' in reablement. In: Ebrahimi VA, Chapman HM, editors. Reablement Services in Health and Social Care. London: Palgrave; 2018:37-74.

6. Ministry of Health and Care Services. A full life - all your life. A quality reform for older persons. 2018. Available from: https:// www.regjeringen.no/contentassets/196f99e63aa14f849c4e4b9 b9906a3f8/en-gb/pdfs/stm201720180015000engpdfs.pdf. Accessed September 11, 2020.

7. National Institute for Health and Care Excellence. Intermediate care including reablement. 2018. Available from: https://www.nice.org.uk/ guidance/ng74. Accessed September 11, 2020.

8. Barnes M, Cotterell P. From margin to mainstream. In: Barnes M, Cotterell $\mathrm{P}$, editors. Critical Perspectives on User Involvement. Bristol: University Press; 2012:xv-xxvi.

9. Askheim OP, Christensen K, Fluge S, Guldvik I. User participation in the Norwegian welfare context: an analysis of policy discourses. J Soc Policy. 2017;46(3):583-601.

10. Hjelle KM, Skutle O, Førland O, Alvsvåg H. The reablement team's voice: a qualitative study of how an integrated multidisciplinary team experiences participation in reablement. J Multidiscip Healthc. 2016;6(9):575-585. doi:10.2147/JMDH.S115588

11. King AII, Parsons M, Robinson E, Jörgensen D. Assessing the impact of a restorative home care service in New Zealand: a cluster randomised controlled trial. Health Soc Care Community. 2012;20 (4):365-374. doi:10.1111/j.1365-2524.2011.01039.x

12. Moe C, Brinchmann BS. Optimising capacity - a service user and caregiver perspective on reablement. Grounded Theor Rev. 2016;15 (2):25-39.

13. Wilde A, Glendinning C. 'If they're helping me then how can I be independent?' The perceptions and experience of users of home-care re-ablement services. Health Soc Care Community. 2012;20 (6):583-590. doi:10.1111/j.1365-2524.2012.01072.x

14. Hjelle KM, Tuntland H, Førland O, Alvsvåg H. Driving forces for home-based reablement; a qualitative study of older adults' experiences. Health Soc Care Community. 2017;25(5):1581-1589.

15. Parsons JGM, Plant SE, Slark J, Tyson SF. How active are patients in setting goals during rehabilitation after stroke? A qualitative study of clinician perceptions. Disabil Rehabil. 2018;40(3):309-316. doi:10.1080/09638288.2016.1253115

16. Rabiee P, Glendinning C. Organisation and delivery of home care re-ablement: what makes a difference? Health Soc Care Community. 2011;19(5):495-503. doi:10.1111/j.1365-2524.2011.01010.x

17. Randström KB, Wengler Y, Asplund K, Svedlund M. Working with 'hands-off' support: a qualitative study of multidisciplinary teams' experiences of home rehabilitation for older people. Int $J$ Older People Nurs. 2014;9(1):25. doi:10.1111/opn.12013 
18. Beresford BA, Neves De Faria RI, Mayhew ET, et al. Outcomes of reablement and their measurement: findings from an evaluation of English reablement services. Health Soc Care Community. 2019;27 (6):1438-1450.

19. Jokstad K, Skovdahl K, Landmark BT, Haukelien H. Ideal and reality; Community healthcare professionals' experiences of userinvolvement in reablement. Health Soc Care Community. 2019;27 (4):907-916. doi:10.1111/hsc.12708

20. Moe A, Ingstad K, Brataas H. Patient influence in home-based reablement for older adults: qualitative research. BMC Health Serv Res. 2017;17:736.

21. Rose A, Rosewilliam S, Soundy A. Shared decision making within goal setting in rehabilitation settings: a systematic review. Patient Educ Couns. 2016.

22. Vik K, Eide AH. The exhausting dilemmas faced by home-care service providers when enhancing participation among older adults receiving home care. Scand J Caring Sci. 2012;26(3):528-536. doi:10.1111/j.1471-6712.2011.00960.x

23. Parsons JGM, Jacobs S, Parsons MJG. Use of goals as a focus for services for community-dwelling older people. In: Siegert RJ, Levack WMM, editors. Rehabilitation Goal Setting. London: CRC Press; 2015:305-324.

24. Brinkmann S, Kvale S. InterViews: Learning the Craft of Qualitative Research Interviewing. 3 ed. Thousand Oaks, Calif: Sage; 2015.

25. Tuntland H, Aaslund MK, Langeland E, Espehaug B, Kjeken I. Psychometric properties of the Canadian occupational performance measure in home-dwelling older adults. $J$ Multidiscip Healthc. 2016;9:411. doi:10.2147/JMDH.S113727
26. Guralnik JM, Simonsick EM, Ferrucci L. A short physical performance battery assessing lower extremity function: association with self-reported disability and prediction of mortality and nursing home admission. J Gerontol. 1994;49:M85-M94.

27. WMA Declaration of Helsinki. Ethical principles for medical research involving human subjects. 2013. Available from: http:// www.wma.net/en/30publications/10policies/b3/index.html.

28. Björkman Randström K, Asplund K, Svedlund M, Paulson M. Activity and participation in home rehabilitation - older people's and family members' perspectives. $J$ Rehabil Med. 2013;45:211-216. doi:10.2340/16501977-1085

29. Gustafsson LK, Anbäcken EM, Elfström M, Zander V, Östlund G. Working with short-term goal-directed reablement with older adults: strengthened by a collaborative approach. Nord J Nurs Res. 2019;39 (4):178-185. doi:10.1177/2057158519850974

30. Birkeland A, Tuntland H, Førland O, Jakobsen FF, Langeland E. Interdisciplinary collaboration in reablement - a qualitative study. J Multidiscip Healthc. 2017;10:195-203. doi:10.2147/JMDH.S133417

31. Mayhew E, Beresford B, Laver-Fawcett A, et al. The Hopkins Rehabilitation Engagement Rating Scale - reablement Version (HRERS-RV): development and psychometric properties. Health Soc Care Community. 2019;27(3):777-787. doi:10.1111/hsc.12696

32. Hammell KW. Perspectives on Disability \& Rehabilitation: Contesting Assumptions; Challenging Practice. Edinburgh: Churchill Livingstone Elsevier; 2006.

33. Malterud K, Siersma VD, Guassora AD. Sample size in qualitative interview studies: guided by information power. Qual Health Res. 2016;26(13):1753-1760. doi:10.1177/1049732315617444
Journal of Multidisciplinary Healthcare

\section{Publish your work in this journal}

The Journal of Multidisciplinary Healthcare is an international, peerreviewed open-access journal that aims to represent and publish research in healthcare areas delivered by practitioners of different disciplines. This includes studies and reviews conducted by multidisciplinary teams as well as research which evaluates the results or conduct of such teams or healthcare processes in general. The journal covers a very wide range of areas and welcomes submissions from practitioners at all levels, from all over the world. The manuscript management system is completely online and includes a very quick and fair peer-review system. Visit http://www.dovepress.com/testimonials. php to read real quotes from published authors. 